\title{
CATARACT EXTRACTION WITH OPTIMUM WOUND CLOSURE*
}

BY

\author{
A. GIARDINI AND G. P. PALIAGA \\ Como, Italy
}

IN the operation of cataract extraction, we have used for several years a large number of corneo-scleral sutures. Operations are carried out in the classical way (corneal incision with a Graefe knife or with keratome and scissors with no conjunctival flap) and the wound is then closed by at least eleven sutures of $10 / 0$ virgin silk using triangular corneal needles of the Vogt-Barraquer type (Grieshaber 81/7). These sutures are not removed. Firm hermetic closure of the wound is thus obtained. This suture technique allowed us to extend our previous observations on the post-operative behaviour of the eye (Giardini and Paliaga, 1961a, b; 1962a, b).

(1) Re-Formation of The ANTerior Chamber.-After cataract extraction, the secondary aqueous restores the anterior chamber, which becomes deeper than before because the absence of the lens causes the iris to recede. If there has been an uneventful post-operative course, re-formation of the anterior chamber is generally seen when the eye is first dressed, about 24 hours after the operation. Information concerning the first 24 hours of the post-operative course has not been conclusive (Kronfeld, 1954; Scheie, 1954) so that the actual time was unknown, but a study of 44 patients (Giardini and Paliaga, 1963) has shown that, when the anterior chamber is hermetically closed, it re-forms within 3 hours at the most.

In 87.5 per cent. of cases the anterior chamber re-formed within 2 hours (Fig. 1), and was usually deep enough to allow drainage from the angle 1 hour after operation.

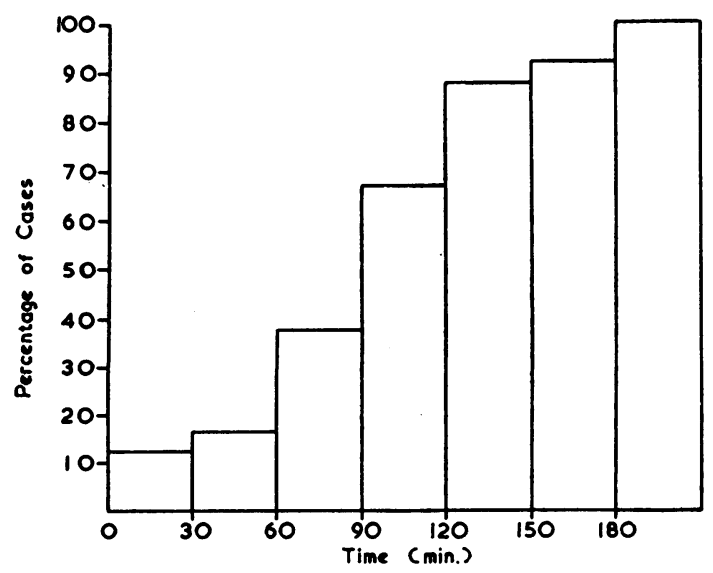

FIG. 1.-Time required for re-formation of anterior chamber.

* Received for publication May 31, 1963. 
Re-formation of the anterior chamber depends on the production of an adequate amount of aqueous:

(1) to replace the amount lost by the opening of the anterior chamber, which is estimated to be no less than $300 \mathrm{cu} . \mathrm{mm}$.;

(2) to fill the space previously occupied by the lens, a volume of at least $200 \mathrm{cu} . \mathrm{mm}$.;

(3) to replace the small quantity of aqueous which flows out when the angle is reopened.

We are fairly sure that in our cases the aqueous was reformed to a total of 500 cu. mm. within 180 minutes at the most. When this is remembered in relation to the fact that the aqueous flows at a rate of approximately $2 \mathrm{ml} . / \mathrm{min}$., we conclude that the production of aqueous immediately after cataract extraction as well as in the first few hours thereafter seems to be unimpaired.

(2) Ocular Tension.-Conflicting opinions will be found in the literature concerning the behaviour of the ocular tension after cataract extraction, and the relevant studies may be divided into two groups. During the early post-operative period, Galin, Baras, and Perry (1961) found the tension to be normal, but Gormaz (1962) reported hypotony. Hilding $(1939,1955)$ and Miller, Keskey, and Becker (1957), dealing with later post-operative periods, agree that hypotony occurs.

The contradictory reports refer to the period following the 8th post-operative hour. There are no data in the literature concerning the interval between the end of the operation and the 8th post-operative hour.

Our observations on 33 eyes (Giardini and Paliaga, 1962b) are given in Table I and in Table II (opposite):

TABLE I

CHANGES IN OCULAR TENSION IN THE FIRST 8 HOURS AFTER OPERATION IN TWENTY CASES

\begin{tabular}{|c|c|c|c|c|c|c|c|c|c|}
\hline \multirow{3}{*}{ Case No. } & \multicolumn{9}{|c|}{ Ocular Tension (mm. Hg) } \\
\hline & \multirow{2}{*}{ Pre-operative } & \multicolumn{8}{|c|}{ Hours after Operation } \\
\hline & & 1 & 2 & 3 & 4 & 5 & 6 & 7 & 8 \\
\hline 3 & 12 & 0 & 0 & 0 & 7 & 10 & 12 & 12 & 12 \\
\hline 8 & 16 & 0 & 0 & 5 & 14 & 14 & 16 & 16 & 16 \\
\hline 10 & 19 & 0 & 0 & 0 & 0 & 10 & 16 & 15 & 20 \\
\hline 12 & 19 & 0 & 0 & 0 & 12 & 19 & 20 & 20 & 19 \\
\hline 13 & 21 & & 0 & 0 & 20 & 30 & 41 & 41 & 41 \\
\hline 15 & 19 & 0 & 0 & 0 & 9 & 16 & 18 & & 24 \\
\hline 16 & 13 & 0 & & 0 & 0 & 12 & & 13 & 13 \\
\hline 18 & 15 & & 0 & 0 & 0 & 7 & 12 & 10 & 10 \\
\hline 19 & 19 & 0 & 0 & 0 & 0 & 12 & 18 & 19 & 19 \\
\hline 21 & 13 & 0 & 0 & 5 & 12 & 15 & 15 & & 19 \\
\hline 22 & 22 & & 0 & 10 & 20 & 24 & 30 & 36 & 40 \\
\hline 23 & 11 & & 0 & 0 & 0 & 12 & & 16 & 17 \\
\hline 24 & 16 & & 0 & 0 & 13 & 16 & 18 & 17 & 21 \\
\hline 25 & 19 & & & 0 & 10 & 16 & 18 & 22 & 21 \\
\hline 26 & 15 & & 0 & 0 & 0 & 0 & 0 & 0 & 0 \\
\hline 27 & 21 & & 0 & 0 & 0 & 0 & 0 & 0 & 0 \\
\hline 28 & 19 & & 0 & 7 & 18 & 19 & 20 & 20 & 22 \\
\hline 29 & 15 & & 0 & 0 & 0 & 0 & 5 & 7 & 10 \\
\hline 30 & 17 & & & 0 & 7 & 16 & 16 & 14 & 16 \\
\hline 31 & 14 & & & 0 & 9 & 9 & 10 & 12 & 14 \\
\hline
\end{tabular}


TABLE II

CHANGES IN OCULAR TENSION FROM THE 8TH HOUR TO THE 4TH MONTH AFTER OPERATION IN 33 CASES

\begin{tabular}{|c|c|c|c|c|c|c|c|c|c|c|c|c|c|c|c|c|c|c|c|c|c|c|}
\hline \multirow{4}{*}{$\begin{array}{l}\text { Case } \\
\text { No. }\end{array}$} & \multicolumn{22}{|c|}{ Ocular Tension (mm. $\mathrm{Hg})$} \\
\hline & \multirow{3}{*}{$\begin{array}{c}\text { Pre- } \\
\text { operative }\end{array}$} & \multicolumn{21}{|c|}{ Post-operative } \\
\hline & & Hrs & \multicolumn{17}{|c|}{ Days } & \multicolumn{3}{|c|}{ Mths } \\
\hline & & 8 & 1 & 2 & 3 & 4 & 5 & 6 & 7 & 8 & 9 & 10 & 11 & 12 & 13 & 14 & 15 & 30 & 45 & 2 & 3 & 4 \\
\hline $\begin{array}{r}1 \\
2 \\
3 \\
4 \\
5 \\
6 \\
7 \\
8 \\
9 \\
10 \\
11 \\
12 \\
13 \\
14 \\
15 \\
16 \\
17 \\
18 \\
19 \\
20 \\
21 \\
22 \\
23 \\
24 \\
25 \\
26 \\
27 \\
28 \\
29 \\
30 \\
31 \\
32 \\
33\end{array}$ & $\begin{array}{l}8 \\
14 \\
12 \\
16 \\
16 \\
12 \\
18 \\
16 \\
19 \\
19 \\
15 \\
19 \\
21 \\
18 \\
19 \\
13 \\
19 \\
15 \\
19 \\
18 \\
13 \\
22 \\
11 \\
16 \\
19 \\
15 \\
21 \\
19 \\
15 \\
17 \\
14 \\
20 \\
17\end{array}$ & $\begin{array}{r}16 \\
20 \\
19 \\
41 \\
24 \\
13 \\
10 \\
19 \\
19 \\
40 \\
17 \\
21 \\
21 \\
0 \\
0 \\
22 \\
10 \\
16 \\
14\end{array}$ & $\begin{array}{r}0 \\
18 \\
12 \\
24 \\
11 \\
12 \\
18 \\
23 \\
15 \\
19 \\
0 \\
20 \\
43 \\
25 \\
16 \\
15 \\
24 \\
14 \\
10 \\
24 \\
18 \\
27 \\
22 \\
16 \\
24 \\
<5 \\
7 \\
24 \\
7 \\
16 \\
16 \\
21 \\
17\end{array}$ & $\begin{array}{r}0 \\
13 \\
12 \\
14 \\
6 \\
11 \\
18 \\
0 \\
17 \\
19 \\
15 \\
18 \\
41 \\
15 \\
16 \\
13 \\
23 \\
8 \\
5 \\
21 \\
15 \\
26 \\
16 \\
9 \\
18 \\
<5 \\
0 \\
17 \\
5 \\
17 \\
14 \\
15 \\
16\end{array}$ & $\begin{array}{r}5 \\
10 \\
12 \\
16 \\
10 \\
12 \\
18 \\
0 \\
16 \\
15 \\
14 \\
19 \\
36 \\
17 \\
13 \\
12 \\
16 \\
<5 \\
0 \\
17 \\
15 \\
24 \\
12 \\
11 \\
14 \\
7 \\
0 \\
13 \\
0 \\
15 \\
21 \\
19 \\
17\end{array}$ & $\begin{array}{r}8 \\
16 \\
11 \\
17 \\
8 \\
12 \\
16 \\
0 \\
18 \\
15 \\
14 \\
19 \\
20 \\
18 \\
16 \\
8 \\
16 \\
0 \\
5 \\
18 \\
16 \\
26 \\
18 \\
10 \\
17 \\
<5 \\
0 \\
9 \\
0 \\
14 \\
15 \\
18 \\
17\end{array}$ & $\begin{array}{r}8 \\
15 \\
12 \\
17 \\
8 \\
8 \\
16 \\
12 \\
15 \\
14 \\
14 \\
20 \\
22 \\
12 \\
15 \\
9 \\
17 \\
16 \\
9 \\
18 \\
13 \\
19 \\
21 \\
11 \\
15 \\
0 \\
19 \\
10 \\
0 \\
14 \\
16 \\
19 \\
18\end{array}$ & $\begin{array}{r}8 \\
14 \\
12 \\
17 \\
<5 \\
5 \\
18 \\
0 \\
18 \\
8 \\
12 \\
26 \\
16 \\
16 \\
16 \\
9 \\
16 \\
0 \\
<5 \\
19 \\
14 \\
19 \\
11 \\
11 \\
17 \\
0 \\
18 \\
11 \\
7 \\
15 \\
13 \\
20 \\
17\end{array}$ & $\begin{array}{r}10 \\
13 \\
12 \\
18 \\
<5 \\
0 \\
17 \\
9 \\
17 \\
5 \\
13 \\
20 \\
14 \\
18 \\
14 \\
14 \\
16 \\
11 \\
<5 \\
13 \\
9 \\
11 \\
10 \\
17 \\
10 \\
19 \\
10 \\
9 \\
15 \\
15 \\
18 \\
16\end{array}$ & $\begin{array}{r}12 \\
14 \\
11 \\
18 \\
0 \\
0 \\
15 \\
15 \\
21 \\
5 \\
12 \\
20 \\
16 \\
17 \\
18 \\
13 \\
\\
0 \\
0 \\
\\
9 \\
9 \\
0 \\
16 \\
12 \\
19 \\
11 \\
13\end{array}$ & $\begin{array}{r}0 \\
0 \\
\\
19 \\
10 \\
0 \\
10\end{array}$ & $\begin{array}{r}\mathbf{0} \\
0 \\
21 \\
11 \\
0 \\
15\end{array}$ & $\begin{array}{r}0 \\
0 \\
14 \\
10\end{array}$ & $\begin{array}{r}<5 \\
0\end{array}$ & $\begin{array}{r}12 \\
0\end{array}$ & $\begin{array}{r}15 \\
0\end{array}$ & $\begin{array}{r}10 \\
15 \\
11 \\
15 \\
15 \\
0 \\
16 \\
14 \\
22 \\
9 \\
16 \\
19 \\
18 \\
17 \\
19 \\
12 \\
17 \\
16 \\
10 \\
19 \\
13 \\
20 \\
11 \\
7 \\
11 \\
15 \\
17 \\
23 \\
13 \\
13 \\
12 \\
20 \\
19\end{array}$ & $\begin{array}{l}10 \\
13 \\
11 \\
17 \\
15 \\
12 \\
15 \\
22 \\
26 \\
21 \\
16 \\
19 \\
17 \\
18 \\
19 \\
11 \\
16 \\
19 \\
20 \\
19 \\
11 \\
19 \\
11 \\
9 \\
13 \\
15 \\
19 \\
25 \\
13 \\
15 \\
13 \\
19 \\
18\end{array}$ & $\begin{array}{l}13 \\
15 \\
12 \\
17 \\
16 \\
12 \\
17 \\
15 \\
22 \\
16 \\
13 \\
19 \\
18 \\
16 \\
19 \\
12 \\
16 \\
16 \\
19 \\
18 \\
13 \\
16 \\
10 \\
13 \\
16 \\
11 \\
20 \\
23 \\
13 \\
17 \\
14 \\
20 \\
16\end{array}$ & \begin{tabular}{|l}
11 \\
14 \\
16 \\
16 \\
16 \\
11 \\
15 \\
15 \\
18 \\
15 \\
13 \\
19 \\
18 \\
18 \\
19 \\
12 \\
18 \\
18 \\
21 \\
18 \\
13 \\
14 \\
13 \\
10 \\
12 \\
13 \\
20 \\
25 \\
14 \\
14 \\
12 \\
18 \\
16
\end{tabular} & $\begin{array}{l}10 \\
16 \\
14 \\
15 \\
15 \\
12 \\
15 \\
16 \\
20 \\
16 \\
13 \\
20 \\
17 \\
19 \\
19 \\
13 \\
19 \\
17 \\
20 \\
19 \\
12 \\
16 \\
11 \\
12 \\
14 \\
12 \\
19 \\
25 \\
15 \\
16 \\
13 \\
20 \\
18\end{array}$ & $\begin{array}{l}11 \\
16 \\
16 \\
16 \\
17 \\
13 \\
18 \\
9 \\
19 \\
16 \\
14 \\
19 \\
18 \\
19 \\
19 \\
13 \\
17 \\
17 \\
18 \\
18 \\
13 \\
19 \\
10 \\
14 \\
15 \\
14 \\
20 \\
21 \\
13 \\
16 \\
14 \\
19 \\
15\end{array}$ \\
\hline
\end{tabular}

(a) After cataract extraction, the tension reaches the pre-operative level within about 7 hours;

(b) In 63.7 per cent. of cases, once the pre-operative level has been reached, it is maintained during the whole of the post-operative course for as long as 4 months;

(c) In $36 \cdot 3$ per cent. of cases, severe hypotensive crises occurred; these were sometimes intermittent, being accompanied by other pathological sequelae, such as signs of leakage of aqueous, alterations in the depth of the anterior chamber, and increased uveal reaction;

(d) In $57 \cdot 5$ per cent. of cases, an initial hypertension of up to $22 \mathrm{~mm}$. $\mathrm{Hg}$ above normal could be observed within the first 24 post-operative hours. In 68.4 per cent. of cases, the tension returned to normal within 48 hours of the operation. An analogous observation was made by Kronfeld (1954) after paracentesis of the anterior chamber.

No hypotension follows an operation for cataract extraction if the post-operative course is perfectly normal; if it does occur it always returns to normal spontaneously, and does not compromise the final result unless some other complication becomes accentuated. Transient post-operative hypotension may pass unobserved if the tension is not regularly measured.

Our observations confirm that the aqueous flow is not impaired after cataract extraction. 


\section{(3) Post-Operative Complications}

(a) Flat Anterior Chamber.-We have studied the number of sutures and type of silk used in 821 eyes.

When we used the ordinary $6 / 0$ silk and applied three to six stitches, the incidence of flat chamber was not related to the number of stitches, but a comparison of the ratio between cases with delayed reformation and cases with collapse of the anterior chamber showed that the greater the number of stitches the smaller the incidence of delayed re-formation and the greater the incidence of collapse (Fig. 2).

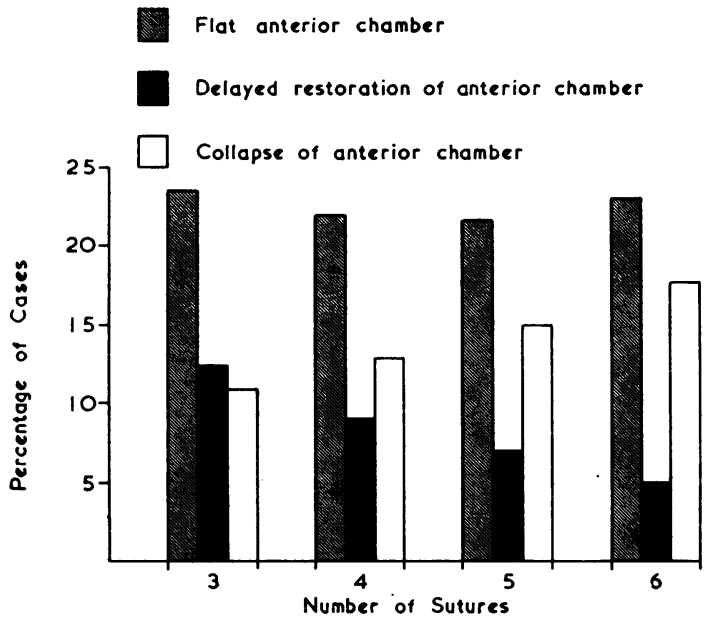

FIG. | 2.--Post-operative complications related to number of sutures used.

We later substituted virgin silk for $6 / 0$ silk, still using five or six stitches, and had fewer cases of collapse of the anterior chamber (Table III); this must be related to the fact that the stitches of virgin silk were not removed but were left to disappear spontaneously.

When we increased the number of stitches to a minimum of eleven, both delayed re-formation and collapse of the anterior chamber became less frequent (Table III). Moreover, if the complication did occur, it lasted for so short a time that further surgical intervention was unnecessary.

TABle III

INCIDENCE OF POST-OPERATIVE FLAT ANTERIOR CHAMBER, BY TYPE AND NUMBER OF SUTURES

\begin{tabular}{|c|c|c|c|c|c|c|c|c|}
\hline \multirow{3}{*}{$\begin{array}{l}\text { Type of } \\
\text { Silk }\end{array}$} & \multirow{3}{*}{$\begin{array}{l}\text { No. of } \\
\text { Sutures }\end{array}$} & \multirow{3}{*}{$\begin{array}{l}\text { No. of } \\
\text { Cases }\end{array}$} & \multicolumn{6}{|c|}{ Anterior Chamber } \\
\hline & & & \multicolumn{2}{|c|}{ Flat } & \multicolumn{2}{|c|}{$\begin{array}{c}\text { Delayed } \\
\text { Re-formation }\end{array}$} & \multicolumn{2}{|c|}{ Collapse } \\
\hline & & & No. & Per cent. & No. & Per cent. & No. & Per cent. \\
\hline $\begin{array}{l}\quad 6 / 0 \\
\text { Virgin } 10 / 0 \\
\text { Virgin } 10 / 0\end{array}$ & $\begin{array}{l}5 \text { or } 6 \\
5 \text { or } 6 \\
11 \text { or More }\end{array}$ & $\begin{array}{l}213 \\
128 \\
300\end{array}$ & $\begin{array}{r}48 \\
19 \\
9\end{array}$ & $\begin{array}{c}22 \cdot 5 \\
14 \cdot 8 \\
3\end{array}$ & $\begin{array}{r}14 \\
8 \\
5\end{array}$ & $\begin{array}{l}6 \cdot 5 \\
6 \cdot 2 \\
1 \cdot 6\end{array}$ & $\begin{array}{r}34 \\
11 \\
4\end{array}$ & $\begin{array}{l}16 \\
8 \cdot 6 \\
1 \cdot 4\end{array}$ \\
\hline
\end{tabular}


Many pathogenic mechanisms may cause absence of the anterior chamber after cataract extraction, but our experience suggests that it is mainly due to leakage of aqueous.

(b) Hyphaema.-The incidence of hyphaema fell from 14.9 to 7 per cent. when the number of stitches was raised from 5 to 7 to at least eleven (Table IV).

(c) Iris Displacement.-This complication did not occur when the usual interval of $25-30^{\circ}$ between the stitches was reduced to $15^{\circ}$ (Table IV).

TABLE IV

INCIDENCE OF HYPHAEMA AND IRIS DISPLACEMENT, BY NUMBER OF SUTURES

\begin{tabular}{c|c|c|c|c|c|c}
\hline \multirow{2}{*}{$\begin{array}{c}\text { Type of } \\
\text { Silk }\end{array}$} & $\begin{array}{c}\text { No. of } \\
\text { Sutures }\end{array}$ & $\begin{array}{c}\text { No. of } \\
\text { Cases }\end{array}$ & \multicolumn{4}{|c}{ Complication } \\
\cline { 3 - 7 } & & & Hyphaema & \multicolumn{2}{|c}{ Iris Displacement } \\
\hline Virgin 10/0 & $5-7$ & 134 & 20 & 14.9 & 4 & 2.9 \\
\hline & 11 or More & 170 & 12 & 7 & 0 & - \\
\hline
\end{tabular}

(4) Further Observations

(a) The stitches need not be removed, thus avoiding a delicate and difficult procedure.

(b) The stitches are very well tolerated by the patient and neither granulomatous formations around the stitches nor abnormal conjunctival reactions have ever been observed.

(c) The firm and hermetic closure of the wound makes post-operative care much easier. Only a uniocular bandage needs to be applied, it is possible to uncover the operated eye on the first or second day after the operation, and the patient needs to remain in bed for only 24 hours, and can usually be discharged on the 5th day.

\section{Summary}

The firm and hermetic closure of the incision with at least eleven stitches of 10/0 virgin silk after cataract extraction has been followed by certain observations on post-operative progress.

The anterior chamber assumes a normal aphakic depth within 3 hours. Intraocular tension regains the pre-operative level within about 7 hours and remains stable. Hypotonic crises occur only if the post-operative course is not perfectly normal.

These findings suggest that the aqueous flow is unimpaired after cataract extraction.

Post-operative complications, such as flat anterior chamber, hyphaema, and iris displacement, are reduced or eliminated, and post-operative care is consequently simplified and shortened. 


\section{REFERENCES}

Galin, M. A., Baras, I., and Perry, R. (1961). Arch. Ophthal. (Chicago), 66, 80.

GiardinI, A. (1962). Docum. ophthal., 16, 338. and Paliaga, G. P. (1961). Boll. Oculist., 40, 335. (1961). Minerva oftal., 3, 105. (1962a). Ann. Ottal., 88, 93. (1962b). Ibid., 88, 551.

- (1963). Ophthalmologica (Basel), 145, 59.

Gormaz, A. (1962). Amer. J. Ophthal., 53, 832.

Hilding, A. (1939). Arch. Ophthal. (Chicago), 22, 171. (1955). Ibid., 53, 686.

Kronfeld, P. C. (1954). Amer. J. Ophthal., 38, 453.

Miller, J. E., Keskey, G. R., and BeCKer, B. (1957). A.M.A. Arch. Ophthal., 58, 401. SCHEIE, H. G. (quoted by Kronfeld, 1954). 